reasonableness of the fees of the National Deposit Friendly Society, and yet we quietly submit to the system of sweating the medical profession which exists all over England. As a country doctor of eight years' experience, with a large club practice, I feel sure no system will ever be found satisfactory alike to doctor and patient where the former receives a fixed annual sum independent of the work done, even though it be $6 \mathrm{~s}$. or more. A doctor's life is of such a harassing nature that it is absolutely necessary, in my opinion, that he should be paid for work done Society. This is all the more necessary now since, owing to the frequent epidemics of influenza, the club doctor's work is increased tenfold. For example, during the recent epidemic, in January alone I dispensed, I
should think, nearly a thoussand bottles of medicine, for which I did not receive an extra penny (that is, practically gave them away), and this receive an extra penny (that is, practically gave them away), and this my experience was by no means singular. If this is not sweating, what my experience was by no means singular. If this is not sweating, what
is? The interests of the patient, quite apart from those of the doctor, deis ? The interests of the patient, quite apart from those of the doctor, de-
mand a change. It is idle to pretend that we do our work properly : we mano a change. It is ide to pretend that we do our work properly : we who will not admit this unpleasant truth. It may be said that there are many of the poorer people (abourers, for example) who could not afford to pay an annual contribution sufficient to defray the cost of the fees above mentioned. This difficulty might easily be got over by the richer branches of the big friendly societies helping their poorer thousands of members who could ensily afford to pay much more. I feel sure the friendly societies will not consent to pay us for work done unless under great pressure. They have been in the habit of sweating us for so long that they are not likely now to give it up. For this reason I think a Conciliation Board is not likely to do much good. There ought to be a minimum fee for club patients fixed, if possible, by the General Medical Council. and any doctor taking less should be considered guilty of infamous conduct and punished accordingly. For be did he takeless, whatever the public might think of it.

\section{ADDRESS REQUIRED.}

DR. HVGH Wooy gerary General Secretary) writes: The Secretary of the London and counties Medical Protection Society, 12, New Court, with the present iddress of Mr. W. $\mathrm{K}$. Willis, bonesetter, recently practising at Tylorstown, South Wales.

EMPLOYMENT OF UNQUALIFTBD ASSISTANTS.

Farr PLAY writes: I am in practice in North Wales, but find to my dismay that there are several medical practitioners in the locality who continue to employ unqualiffed persons as assistants (in one case two are employed). Such persons visit, treat, and vaccinate in the district. where they are known as Dr. So-and-So. I am fully aware that if such cases were brought before the General Medical Counil and substantiated by statutory declaration the complaints would at once be investigated; but this would lead undoubtedly to the erasion of the names of the medical practitioners from the Register, and the full penalty would be enforced, which is more severe than I should wish.

There is no diffculty now in obtaining qualified assistants, but we (the qualified ones) expect a reasonable remuneration, and if. as it is so often stated, we do less work, it is done conscientiously. Is there no carrying out the laws they make?

* * We are not sure that we understand our correspondent's point. It is true that the only punishment which the General Medical Council can inflict is erasure from the Register, but it has frequently, in cases in which the charge has been proved, admonished the offender and suspended judgment, to afford him an opportunity to reconsider his position.

The TREATMent OF DipHTHeria.

DR. A. JEFFERIS TURNER (Brisbane) asks us to publish the following corpublished in the BRITISH MEDICAL JovRNAL of December 30 th, 1899 , p. 1789 , col. 2 :

Mortality of all Cases of Diphtheria at each Year of Life treated in the Hospital for Sick Childrem Brisbane before and after the Introduction of Antitoxin.

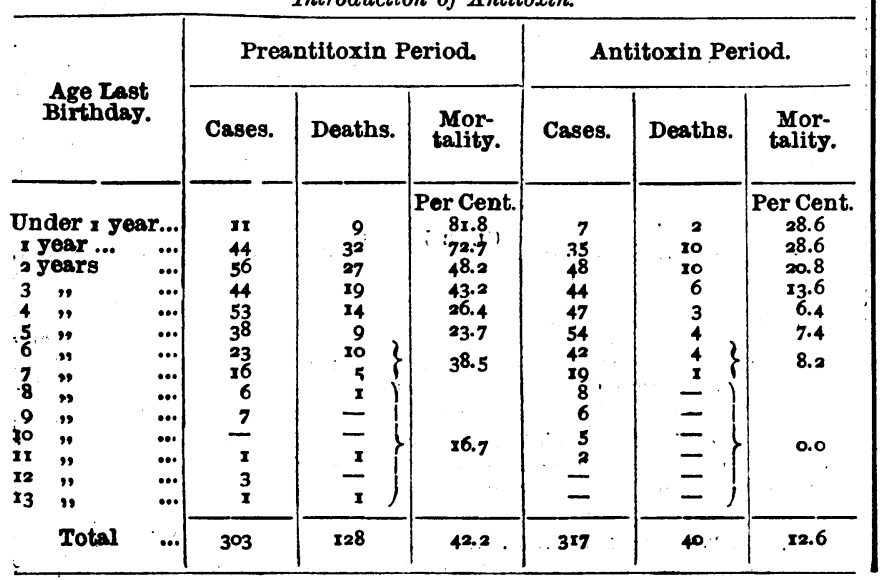

L.R C.P.L. writes: Ulcer of the anus and rectum may be speedily and painlessly cured, without using the knife or caustics. Let the patien lie in bed during six or seven days, taking a low diet, and preventing all evacuation by the bowels. On the soventh day give an aperient dose. say of castor oil, to be followed in a short interval with a softening
enema to promote defæcation. This will be quite painless, as by this enema to promote defæcation. This wi.
time all trace of ulceration will be gone.

Sodidm Saticylate Poisoning.

DR. A. C. BARron, (Dailly, Ayrshire) sends us a case of poisoning with salicylate of soda in a pationt suffering from acute pleurisy, and closely resembling in its symptoms that recorded by Dr. Ainslie Scott, in the BRITISB MEDICAI JOURNAL of February 3 rd, rgoo. The man, who was a Bealthy ploughman, oontracted pleurisy after exposure in a ploughing match. He was given 3 drachms of the drug in the course of three days. he became noisy and restless, developing hallucinations of sight and hearing. He was with diffeulty kept in bed ; he imagined that pin with the enrust in his temperature, and under the exhibition of sedatives, the untoward symptoms passed off.

LETTERS, COMMUNIOATIONS, ENO., have boen recelved trom A Author; Mr. J. Y. W. Macalister, London; Professor T. Cliford Allbutt, Cambridge. B Mr. W. L'H Blenkarne, Worthing; Mr. H. Brown, Leeds; J. O. Brown, M.B., London; Mr. R. J. Bland, London ; Dr. F. Beach, Kingston Hill ; Dr. G. Buchanan, Glasgow; Dr. R.J. M. Buohanan, Liverpool; B. G.; Mr. J. R. Buchanan, Glasgow; Mr. P. D. Barker, Rochester. C A. Oax, M.B.. Gateshead; C. C ; Dr. J. M. Olarke, Bristol ; Dr. H. Campbell, London : Dr. D. P. H. Cunningha: D, New York ; Dr. W. H. Oorfield, London; OClllery, Doctor of the North; Colliery Surgeon; Oourt Fees. D J. Dunbar-Brunton, M.B., Leatherhead; Dr. T. Dutton, London; Dr. J. R. W., India; Derbyehire; Dr. A Duke, Cheltenham; Dr. L. Drage, Hatfield. T Enquirenk.

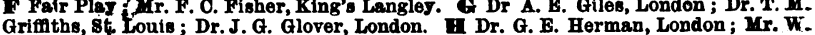
F. Haslam, Birmingham ; Dr. P. Horrocks, London; Harveian soclety of London, Secretary of, London; Mr. A. E. Hayward.Pinch, London: T. B. Hayward, M.B., Haydock; Dr. . . M. Hasbrouch, Washington. D.C. I I.M.S. J Dr. N. B. Jenkins,

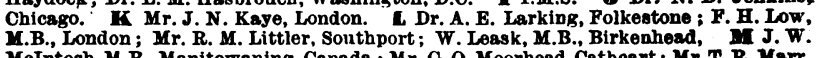
McIntosh. M.B., Manitowaning, Canada ; Mr. G. O. Moorhead, Catbcart; Mr.T. R. Marr, London; Mr. A. H. Milne, London; Dr. H. J. Macevoy, London ; Manchester Pathological society, secretary of, Manchester ; Military Correspordent; Mr G. Maolay, Secretary of, Nottingham ; Dr. D. Newman, Glasgow. P P Dr. P. H. Pye-Smith. London ; Mr. C. E. Paget, Northampton; Mr.J. F. Pink, London; Dr. C. H. Phillips, Hanley; Mr. J. R. Philpots, Parkstone; Mr. W. Paget-Tomlinson, Kirkby Lonsdale: Dr. T. D. Poole, Wolverhampton. R Dr. A. Routh, London; T. E. F. Roddis, M.B., King's Lynn; Dr. G. D. Kobinson, London; Dr. G. H. Rodman, East Sheen; Mr. P:
Rustoniji, Bombay; Reader; R. B. B. M. Sheild, M.B., London; Student; Rustoniji, Bombay; Reader; R. R A. M. Sheild, M.B., London; student;
S. M. V.; A. J. B. Squire, M.B., London: Dr. J. A. Shaw-Mackenzie, London. T Dr. A. J. Turner, Brisbane: ' T. P.; "Tuberculosis," Editors of, London.

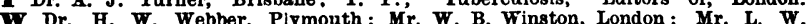
Williams, Glasgow; W. F.; Mr. E.jM. Wrench, Baslow. $X$ Mr. G. Yeoman, Northallerton.

\section{BOOK8, ETo., KECEIVED.}

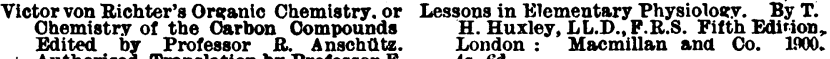

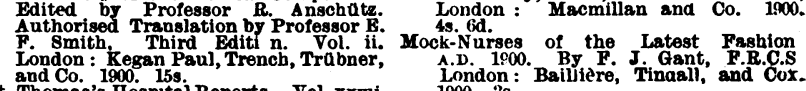

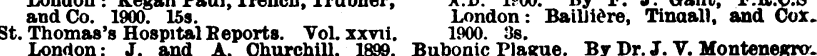

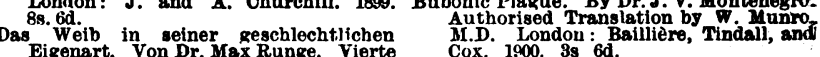

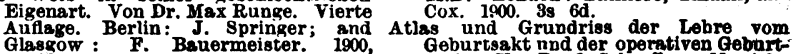

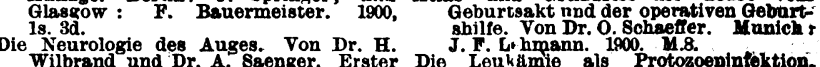

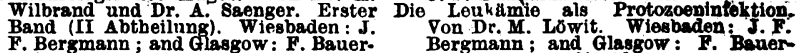

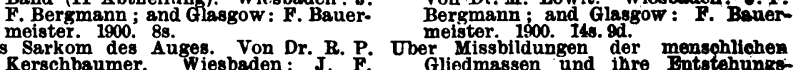

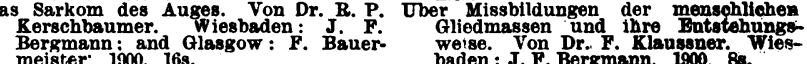

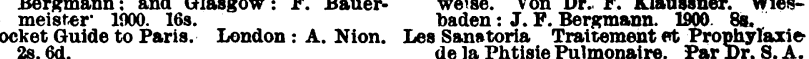

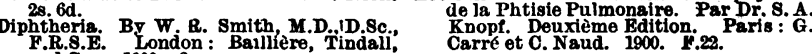
$\because *$ In forwarding books the publishers are requested to stale the selling price.

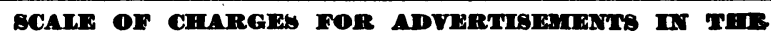
BRITISH MEDICAI JOURRAT.

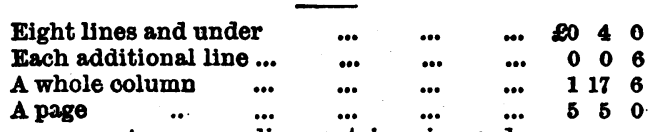

An uverage line contains six words.

Advertisements should be delivered, addressed to the Manager, at the Office, not later than first post on Wednesday morning preceding publica. tion; and if not paid for at the time, should be accompanied by a reference, Post-Office Orders should be made payable to the British Medical Association at the General Post-Office, London. Small amounts may bo paid in postage-stamps.

N.B.-It is against the rules of the Post Office to receive letters at Poetes Resiantes addressed either in initials or numbers. 